https://helda.helsinki.fi

\title{
Bicycle helmet effectiveness is not overstated
}

\section{Olivier, Jake}

2017

Olivier , J \& Radun , I 2017 , ' Bicycle helmet effectiveness is not overstated ' , Traffic injury prevention , vol. 18 , no. 7 , pp. 755-760 . https://doi.org/10.1080/15389588.2017.1298748

http://hdl.handle.net/10138/310071

https://doi.org/10.1080/15389588.2017.1298748

Downloaded from Helda, University of Helsinki institutional repository.

This is an electronic reprint of the original article.

This reprint may differ from the original in pagination and typographic detail.

Please cite the original version. 
See discussions, stats, and author profiles for this publication at: https://www.researchgate.net/publication/316480378

\section{Bicycle helmet effectiveness is not overstated}

Article in Traffic Injury Prevention · March 2017

DOI: 10.1080/15389588.2017.1298748

CITATIONS

5

2 authors:

1. Jake Olivier

164 PUBLICATIONS 2,260 CITATIONS

SEE PROFILE

Some of the authors of this publication are also working on these related projects:

Project My blog View project

Drunk driving View project
READS

353

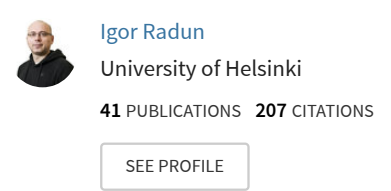




\section{Bicycle helmet effectiveness is not overstated}

Jake Olivier ${ }^{1}$, Igor Radun ${ }^{2,3}$

${ }^{1}$ School of Mathematics and Statistics, University of New South Wales, Australia

${ }^{2}$ Human Factors and Safety Behavior Group, Department of Psychology and Logopedics, Faculty of Medicine, University of Helsinki, Finland

${ }^{3}$ Stress Research Institute, Stockholm University, Sweden

Citation: Olivier J, Radun I. Bicycle helmet effectiveness is not overstated. Traffic Injury Prevention, in press.

Available at: http://www.tandfonline.com/doi/full/10.1080/15389588.2017.1298748.

DOI: $10.1080 / 15389588.2017 .1298748$ 


\begin{abstract}
Objective: To discuss the challenges in estimating bicycle helmet effectiveness from case-control studies of injured cyclists and to estimate helmet effectiveness from cases and available exposure data.
\end{abstract}

Methods: Data were extracted from studies of cyclists in Seattle, USA, Victoria and New South Wales (NSW), Australia and the Netherlands. Estimates of helmet use were used as exposure to compute relative risks for Seattle and Victorian data. Cycling distance data are routinely collected in the Netherlands; however, this data cannot be disaggregated by helmet use which makes it unsuitable for estimating helmet effectiveness. Alternative controls were identified from larger cohorts for the Seattle and NSW cases.

Results: Estimates of helmet effectiveness were similar from odds ratios using hospital controls or from relative risks using helmet use estimates (Seattle: $O R=0.339, R R=0.444$; Victoria: $O R=0.500$, $R R=0.353$ ). Additionally, the odds ratios using hospital controls were similar when controls were taken from a larger cohort for head injury of any severity (Seattle: $O R=0.250$, alt $O R=0.257$; NSW: $O R=0.446$, alt $O R=0.411$ ) and for serious head injury (Seattle: $O R=0.135$, alt $O R=0.139$; NSW:

$\mathrm{OR}=0.335$, alt $\mathrm{OR}=0.308$ ). Although relevant exposure data were unavailable for the Netherlands, the odds ratio for helmet effectiveness of those using racing, mountain or hybrid bikes was similar to other estimates $(\mathrm{OR}=0.371)$.

Conclusions: Despite potential weaknesses with case-control study designs, the best available evidence suggests helmet use is an effective measure of reducing cycling head injury.

Keywords: bicycle helmet; case-control; cohort studies; odds ratio; relative risk; incidence rate ratio

Abstract: 227 words

Manuscript: 3882 words

Figures: 1

Tables: 3 


\section{BACKGROUND}

There are numerous health and environmental benefits to cycling, although it is not without risk of injury. Head injuries, common in cycling crashes, can lead to life-long disability and even fatality. Bicycle helmets have been proposed as a means to lower the risk of head injury, although strategies to increase helmet use, through either promotion or legislation, are seen by some to be controversial.

A recent systematic review and meta-analysis of studies assessing bicycle helmet effectiveness found large odds reductions of $51 \%$ for head injury, $69 \%$ for serious head injury and $65 \%$ for fatal head injury associated with helmet use (Olivier and Creighton, 2017). Although a previous metaanalysis found evidence of publication and time trend bias as well as an increase in the odds of neck injury for helmet wearers (Elvik 2013), the latest review using data from over 64,000 injured cyclists did not support these findings. Additionally, many sensitivity analyses were performed with little change to the overall results.

There are challenges to accurately estimating bicycle helmet effectiveness since randomised controlled trials are not possible on ethical grounds. Additionally, the recent systematic review did not identify any large cohort studies, which is likely due to the prohibitive nature in collecting relevant data. Case-control study designs are the standard in this area with cases (head injured) and controls (non-head injured) collected from combinations of hospital, emergency department, trauma centre and police records. There are potential weaknesses with these study designs. The odds ratio is the only measure of comparative risk that can be reasonably calculated and cycling crashes without a medically diagnosed injury are excluded. Instead, controls are selected from those with "other" injuries (Marshall 2008).

Although randomised controlled trials for helmet effectiveness are not possible, there have been several biomechanical studies using dummy tests or computer simulation. In a dummy test simulating a $20 \mathrm{~km} / \mathrm{h}$ crash, Cripton et al. (2014) found the probability of a serious head injury was a near certainty for an unhelmeted cyclist and near a 9\% probability when a helmet was worn. In another dummy test, McIntosh et al. (2013) found helmet use lessened both linear and angular acceleration while McNally and Whitehead (2013) similarly found helmets were efficacious from computer simulations of bicycle crashes.

A recent publication (Zeegers 2015) claims "any case-control study in which the control is formed by hospitalized bicyclists is unreliable and likely to overestimate the effectiveness of the bicycle helmet" and concludes "[c]laims on the effectiveness of the bicycle helmet can no longer be supported by these kind of studies" (p. 1). This study has initiated many discussions regarding past bicycle helmet research that has led some to dismiss claims helmets are effective at mitigating head injury (see, for example, Woolsgrove 2015). Although not explicitly stated in the text, Zeegers has derived and computed estimates that are equivalent to the incidence rate ratio using distance travelled as the exposure and the relative risk using proportions of helmet wearers. These measures are commonly used in epidemiology (for example, see Greenberg et al. 2001).

In this paper, we will briefly discuss the challenges in estimating bicycle helmet effectiveness from case-control studies, reanalyse the data used by Zeegers' as a basis for our discussion, provide 
evidence that odds ratios using hospital controls likely underestimate helmet effectiveness, and propose areas of further study.

\section{CASE-CONTROL STUDIES ASSESSING HELMET EFFECTIVENESS}

A consequence of case-control studies is that many measures of comparative risk cannot be directly computed such as the relative risk, risk difference or incidence rate ratio (Sistrom and Garvan 2004). The odds ratio is the only comparative risk measure that can be reasonably calculated. Although there is nothing inherently wrong with the odds ratio as a measure of comparative risk, it is commonly misinterpreted as a relative risk (Holcomb et al. 2001). This is problematic, as it is well known the odds ratio overestimates the relative risk except for rare events (Zhang and Yu 1998).

A representation of the data collected in a case-control study is given in Table 1 where $a, b, c$ and $d$ are the observed frequencies for each cell. The estimated odds ratio $(O R)$ using this notation is

$$
O R=\frac{a / c}{b / d}=\frac{a d}{b c}
$$

It is possible to convert the odds ratio to the relative risk $(R R)$ if the probability of head injury $p_{0}$ is known for the unhelmeted group. That is,

$$
R R=\frac{O R}{1-p_{0}+p_{0} O R}
$$

It is also possible to interpret the odds ratio as an incidence rate ratio under certain assumptions (Greenberg et al. 2001).

Most cycling crashes or falls are not captured by any database and are therefore not included in helmet effectiveness studies. This usually only affects the selection of controls as accurate identification of cases require a medical diagnosis. Therefore, the data from case-control studies can only estimate an upper bound for $p_{0}$ which makes accurate conversion difficult. For example, the proportion of cyclists with diagnosed serious head injury among non-helmet wearers was 0.18 using data from the recent review (Olivier and Creighton, 2017). Using the estimated odds ratio of 0.31 , the converted relative risk is 0.35 . Therefore, the most conservative estimate for the reduction in the risk of serious head injury is $65 \%$ when a helmet is worn.

The use of "other injuries" as controls is also a challenge to accurately estimating helmet effectiveness (Marshall 2008). The ideal outcome for controls is the odds of wearing a helmet among uninjured cyclists in a crash or fall. However, the data from these instances are never collected. Instead, the odds of helmet wearing are computed among cyclists with injuries that would not be affected by helmet use. This is an acceptable approach when the odds using "other injuries" is similar to the population odds. The use of "other injuries" for controls is likely a poor approach when helmet use influences the probability of injury in that group. This can happen, for example, when controls are comprised of those without serious head injury that may include those with facial injury. 


\section{COHORT STUDY DESIGNS AND IMPROVED MEASURES OF RISK}

Cohort study designs are possible for estimating bicycle helmet effectiveness, which would allow for estimation of the relative risk or incidence rate ratio depending on the data collected. The relative risk can be computed using the numbers of helmeted $\left(n_{h}\right)$ and unhelmeted $\left(n_{n h}\right)$ cyclists or the proportions of helmeted $\left(p_{h}\right)$ and unhelmeted cyclists $\left(p_{n h}=1-p_{h}\right)$,

$$
R R=\frac{a / n_{h}}{c / n_{n h}}=\frac{a / p_{h}}{c / p_{n h}}
$$

The use of proportions follows from the relationships $n_{h}=N p_{h}$ and $n_{n h}=N p_{n h}$ where $N=n_{h}+$ $n_{n h}$ is the total (unknown) number of cyclists in a given sample/population. This simplification can be useful; however, confidence intervals and hypothesis testing are not possible because the log relative risk variance cannot be computed from cases and proportions of cyclists only,

$$
\operatorname{var}(\log R R)=\frac{1}{a}-\frac{1}{N p_{h}}+\frac{1}{c}-\frac{1}{N p_{n h}}
$$

The incidence rate ratio can be computed using the distance travelled for helmeted $\left(d_{h}\right)$ and unhelmeted $\left(d_{n h}\right)$ cyclists,

$$
I R R=\frac{a / d_{h}}{c / d_{n h}}
$$

Importantly, accurate estimation of the risk or incidence rate requires the numerator and denominator represent the same sample or population. Inaccuracies can occur, for example, if cases are taken from one of many possible hospitals while the denominator has been estimated for the entire jurisdiction. This error can also occur when cases and exposure do not match on other demographic, temporal or geographic variables.

Estimates of risk measures for different subgroups such as age or type of cyclist can be found using generalised linear modelling. For example, if we let $\mu_{i j}$ be the mean number of cases for helmet use $i=0,1$ and type of cyclist $j=0,1$ and let $e_{i j}$ be a measure of exposure (e.g., number of cyclists or distance travelled for group $i j$ ), a Poisson regression has the form

$$
\log \mu_{i j}=\beta_{0}+\beta_{1} \text { helmet }_{i}+\beta_{2} \text { type }_{j}+\beta_{3} \text { helmet }_{i} \times \text { type }_{j}+\log e_{i j}
$$

We have considered only two types of cyclists for simplicity and a meaningful categorisation of cyclists requires more complexity (Dill and McNeil 2013). The interaction term in this model is an assessment of whether helmet effectiveness differs by cyclist type. If the interaction term is found to be important, helmet effectiveness should be estimated for each type of cyclist. For cyclists of type $_{j}=0$, the log rate ratio is 


$$
\log \frac{\mu_{10}}{e_{10}}-\log \frac{\mu_{00}}{e_{00}}=\beta_{1}
$$

while for cyclists of type $e_{j}=1$,

$$
\log \frac{\mu_{11}}{e_{11}}-\log \frac{\mu_{01}}{e_{01}}=\beta_{1}+\beta_{3}
$$

Confidence intervals can then be constructed using standard likelihood-based methods.

As noted above, the latest systematic review did not identify any cohort studies that assessed bicycle helmet effectiveness. This is likely due to the difficulty in collecting relevant data. Although cases could easily be identified, for example, in jurisdictions that routinely collect hospital data, helmet use and exposure are not often collected. This problem is exacerbated for an analysis of helmet effectiveness by cycling type (e.g., utilitarian, commuter, recreation, sport cyclists) as cases and exposure would need to be known for each helmet use by cycling type subgroup.

There are advantages and disadvantages to both case-control and cohort study designs. The advantages of case-control designs include a more efficient use of resources for rare events (e.g., bicycle crashes), data are more reliable as crashes would be proximal to data collection, and odds ratios computed from both designs are likely to be similar if the probability of a crash is unrelated to helmet use (Cummings et al. 2006). However, if helmet use and crashes are related, measures of risk from cohort study designs are more appropriate since data are collected irrespective of a crash. Additionally, cohort studies allow risk to be measured relative to an exposure such as cycling distance travelled. Cohort studies, however, are susceptible to recall bias with regard to helmet use and exposure and there is increased uncertainty in risk estimates if they are estimated from the population. Note that confounding could be problematic for both study designs and the researcher should take appropriate steps for minimising its influence on the analysis. Finally, there is no guarantee the odds ratio from a case-control design overestimates the relative risk from a cohort study as we will demonstrate later in the paper.

\section{SOURCES OF DATA}

Zeegers (2015) presents three examples of case-control studies with data collected in Seattle, USA for children (Thompson et al. 1989), Victoria, Australia (McDermott et al. 1993), and the Netherlands (Ormel et al. 2008). The Dutch data were supplemented by estimates of cycling distance travelled for helmeted and unhelmeted cyclists (Mobiliteits Onderzoek Nederland 2008) while estimates of helmet use were available for Australian (Cameron et al. 1992) and US data (DiGiusseppe et al. 1989). The author erroneously attributes Robinson (1996) as the source of helmet wearing estimates in Victoria, Australia. Details of the data collected in these jurisdictions are given below. In each instance, data were extracted from the source material for reanalysis.

Additional data are presented for cyclists injured in a motor vehicle crash in New South Wales (NSW), Australia (Bambach et al. 2013) and the Seattle data for all ages (Thompson et al. 1989). In both instances, the authors include hospital controls and those from a larger cycling cohort. For 
NSW, the alternative controls were injured cyclists reported to the police while the Seattle controls were selected from members of the Group Health Cooperative of Puget Sound who responded to a survey regarding cycling and helmet use.

\section{Seattle, USA}

Data on cycling injuries were collected for cyclists presenting to one of five major hospitals in the Seattle area during the period December 1986-November 1987 (Thompson et al. 1989). The reported data includes the number of head injuries by age group $(\leq 14,15-24, \geq 25)$ and helmet use. Helmet use data for school-aged children was collected in the Seattle area with two observational studies, May and September 1987, occurring during the data collection period for cycling injuries (DiGuiseppi et al. 1989).

Note that in Table 5 of Zeegers (2015), the citation and the numbers of cases/controls are from another paper on facial injuries and helmet use by the same authors (Thompson et al. 1990). Although both papers use data from the same sample of Seattle cyclists, Zeegers appears to have extracted and analysed incorrect data. In addition, the analysis relies only on the May 1987 helmet use survey and does not consider the effect the September 1987 survey has on the analysis. The implications of these errors will be discussed later.

\section{Victoria, Australia}

Cycling injury data were collected from April-December 1987 and September 1988-May 1989 for cyclists presenting to public hospitals in Melbourne and Geelong (McDermott et al. 1993). The data set also includes cyclists who died prior to hospital arrival. The numbers of head injuries by helmet use for cyclists of all ages are presented separated by helmet type (approved vs. unapproved) and Abbreviated Injury Severity categories (AIS1+ and AIS3+). Helmets that did not meet the Australian Standard have been excluded from our analysis. Unapproved helmets could include those using obsolete technology (e.g., no shell, foam or leather) and are therefore not relevant to our analysis. Note that Zeegers included cyclists with unapproved helmets in his analysis.

According to Zeegers (2015), the proportion of cyclists wearing helmets of $22.6 \%$ was provided by Dorothy Robinson through a personal communication. A review of the literature indicates estimates of helmet wearing in Victoria were published by researchers at Monash University Accident Research Centre (MUARC) (Cameron et al. 1992; Finch et al. 1993; Cameron et al. 1994). Robinson was not a co-author or acknowledged on any of these publications, so the accuracy of her estimate of helmet wearing is not clear.

Cameron et al. (1992) report estimates of helmet wearing from a collection of surveys conducted by VicRoads, MUARC and Melbourne University students. They give overall estimates of helmet wearing for Victoria of 5\% for 1982/83, 31\% for 1989/90 and $75 \%$ for $1990 / 91$ with yearly estimates given in their Figure 8. The overall estimated proportion of cyclists wearing helmets in Victoria varies between $23-27 \%$ for years 1987-1989. Some caution should be exercised when interpreting these estimates as the proportions varied greatly among age groups, types of cyclists and Melbourne versus Country cities (Cameron et al. 1994). For example, only $8 \%$ of adult recreation cyclists in Melbourne for 1987 were observed to wear a helmet, while adult commuters in Melbourne were over $30 \%$ for the entire study period. The largest helmet wearing rates were for children commuting 
to school (over $70 \%$ for Melbourne and $56 \%$ in country cities). We chose an overall helmet wearing rate of $25 \%$ for our analysis (i.e., midpoint of the range of overall estimates); however, given the uncertainty in the real rate, we created a plot of the relative risk for varying proportions of helmet wearing as a sensitivity analysis.

\section{The Netherlands}

Data were collected from injured cyclists presenting to 13 emergency departments who participate in the Dutch Injury Surveillance System from February to June 2008 (Ormel et al. 2008).

Questionnaires were sent to 2,975 cyclists with 1,142 returning valid responses. The analysis was further limited to 723 injured cyclists in a single-bicycle crash. This information can be found in the English summary of the report.

Regarding helmet usage, the information is only available in Dutch. With the help of Google translate, we found 88 helmet wearers rode racing, mountain or hybrid bikes ( $p .80)$ and these cyclists constituted $96 \%$ of all helmet wearers (Ormel et al. 2008). Therefore, there were 92 cyclists who wore a helmet, four helmeted cyclists who did not ride racing, mountain or hybrid bikes and $13 \%$ of all cyclists wore a helmet. However, Zeegers reports quite different numbers in his paper. He reports more cyclists in his data (732 vs 723 ) and fewer wearing a helmet ( 81 vs 92 ). Zeegers states his numbers were derived from the source data, so it is unclear which data are correct.

Ormel and colleagues (2008) report 155 cyclists were riding a racing, mountain or hybrid bike with 88 wearing a helmet and 67 who were not. Head or neck injuries were reported for $14 \%$ of helmet wearers and $30 \%$ of non-wearers. This information can be used to construct the numbers of cases and controls by helmet wearing for those riding racing, mountain or hybrid bikes. However, the authors do not supply enough information to reconstruct injury counts for riders of other bike types or to separate neck from head injuries. The inclusion of neck injuries is not problematic if bicycle helmets reduce the probability of neck injury; however, helmets have a neutral effect on neck injury (Olivier and Creighton, 2017) which can lead to an underestimation of helmet effectiveness to reduce head injury.

Regarding data on cycling distance, not all injured cyclists were riding racing, mountain or hybrid bikes, although Zeegers assumes only sport cyclists wear helmets. Note that if this claim is correct, i.e., there is no data on helmeted non-sport cycling, helmet effectiveness cannot be estimated for non-sport cycling. Further, Zeegers assumes estimates of helmet wearing among injured cyclists using racing, mountain or hybrid bikes (50-75\%) is a valid estimate for the population proportion of helmet wearers. If bicycle helmets are effective, the estimates from case-control designs will likely underestimate the population proportions. Additionally, Zeegers assumes those riding racing, mountain or hybrid bikes identify as "sport" cyclists, although the type of cycling is unknown for these crashes or falls. Therefore, the estimate of cycling distance for different cycling types by helmet wearing is likely inaccurate using this data.

\section{New South Wales, Australia}

NSW data from police reports and hospitalisations were linked for cyclists involved in a motor vehicle collision for years 2001-2009 (Bambach et al. 2013). Helmet use was reported in the police record and diagnosed head injuries were found in hospital data. Head injuries were put into three 
severity categories (moderate, serious and severe) and those with "other injuries" are available among hospitalisations and those reported to police. Since the data sets were linked, the hospital controls are a proper subset of the police reported controls.

Neither helmet use nor distance travelled by bicycle is available for NSW during the study period. The most recent estimates of helmet wearing for NSW were $74 \%$ for children and $83 \%$ for adults (Smith and Milthorpe 1993).

\section{ESTIMATES OF HELMET EFFECTIVENESS}

The data extracted from the Seattle and Victorian studies are given in Table 2. In each case, odds ratios were computed using hospital controls (Eq. 1) and the relative risk using the estimated proportion of helmet wearers (Eq. 3). With one exception, the relative risk is uniformly smaller (i.e., greater estimated helmet effectiveness) than the odds ratio. For cycling head injury, the relative risks vary from 0.333 to 0.444 for head injury of any severity and 0.339 for serious head injury. Additionally, these estimates of helmet effectiveness are all smaller than Zeegers' estimates using incorrect data.

We chose a helmet wearing rate of $25 \%$ for Victoria in our analysis although it was clear helmet wearing changed dramatically during the study period and differed substantially among subgroups. Estimates for each subgroup are not possible since injury and helmet wearing data are not available in disaggregation. As a sensitivity analysis, we plotted the estimated relative risks by proportion of helmet wearing (see Figure 1). Since the overall helmet wearing rate in Victoria was not below $20 \%$ during the study period, all possible relative risk estimates are smaller than the odds ratio estimates using hospital controls.

Regarding the Dutch data, it is not possible to recreate the counts of injuries for cyclists who did not use racing, mountain or hybrid bicycles. Additionally, the distance travelled is unknown for cycling types by helmet use. It is therefore unreasonable to compute the incidence rate ratio for helmet effectiveness for sport or other cyclists. However, the odds ratio for helmet effectiveness for those using racing, mountain or hybrid bikes is $0.371(95 \% \mathrm{Cl}: 0.166,0.828, p=0.013)$ which is similar to other studies.

Injury data for Seattle across all ages and NSW cyclists in a motor vehicle crash is given in Table 3. In each instance, the odds ratios of helmet effectiveness using hospital controls are similar to controls taken from a larger cohort of cyclists.

\section{DISCUSSION}

There are many methodological challenges in estimating bicycle helmet effectiveness. The primary reason lies with lack of randomisation followed by a lack of large cohort studies of cycling injury. Case-control studies are the norm in this research area with a recent meta-analysis of 40 studies estimating odds reductions of $51 \%$ for head, $69 \%$ for serious head, $33 \%$ for face and $65 \%$ for fatal 
head injuries (Olivier and Creighton, in pres2017s). Due to the challenges involved in estimating helmet effectiveness, it is reasonable to investigate whether these estimates are overstated.

A recent paper claims odds ratios using hospital controls overestimate helmet effectiveness (Zeegers 2015). In a careful review of this article, we found the reported data were usually in conflict with the source material and, when corrected, the relative risks generally estimated greater reductions in head injury than odds ratios. Similarly, odds ratios of head injury were similar whenever using hospital controls or alternative controls taken from a larger cycling cohort regardless of injury severity. The incidence rate ratio, as computed by Zeegers, is likely incorrect since travel distances were not estimated by helmet use and cycling type.

It has long been argued by injury epidemiologists that odds ratios using hospital data underestimate the true effectiveness of helmet use since most cycling crashes are not reported (Thompson et al. 1989). Furthermore, recent research suggests helmet effectiveness estimates are underestimated due to either wearing a damaged helmet or the helmet is worn incorrectly (Bromell and Geddis, 2017). This is an important finding as other researchers have found poorly fit helmets do not perform well (Romanow et al. 2014). Helmet fit is rarely if ever accounted for in case-control studies and it is likely some injured cyclists identified as helmet wearers in case-control studies wore their helmet incorrectly.

Our knowledge of bicycle helmet effectiveness could be greatly improved with other study designs. The most recent review was far larger than the penultimate analysis ( 40 vs 20 studies, $64 \mathrm{~K}$ vs $19 \mathrm{~K}$ injured cyclists) and the summary results were similar to past reviews for head and face injury of any severity and serious head injury. That is, more data largely confirmed previous results for cyclists in a crash or fall.

Two important, unanswered research questions are whether helmet use is associated with a crash or fall and whether helmet effectiveness differs for different cycling types. These questions cannot be thoroughly examined from previously used study designs. Case-control studies cannot estimate the probability of a crash or fall while there is a paucity of research examining the link between helmet use and crashes through a possible mediating mechanism such as risk compensation. For countries that routinely collect all hospital data, incidence rates could readily be computed if exposure data were also collected by helmet use and demographic variables. However, cycling type is not identifiable in the various versions of the International Classification of Diseases (ICD) and accurate identification of cases would require more resources.

Irrespective of existing challenges, the best available evidence suggests helmet use is an effective measure of reducing cycling head injury. There is also a paucity of evidence suggesting helmet use increases injury of any kind. Therefore, strategies to increase bicycle helmet use should be explored until more and better data demonstrates the opposite.

\section{ACKNOWLEDGEMENTS}

This study has not received direct funding although it was carried out within the project on cyclist crashes partly supported by the Traffic Safety Committee of Insurance Companies (VALT), Finland. 
The funders had no role in the conception, design, analysis, interpretation of data, or the writing of this article.

\section{REFERENCES}

Bambach MR, Mitchell RJ, Grzebieta RH, Olivier J. The effectiveness of helmets in bicycle collisions with motor vehicles: A case-control study. Accid Anal Prev 2013; 53: 78-88.

Bromell RJ, Geddis DC. Child cyclists: a study of factors affecting their safety. J Paediatr ChildHealth. 2017;53:145-148.

Cameron M, Heiman L, Neiger D. Evaluation of the bicycle helmet wearing law in Victoria during its first 12 months. Monash University Accident Research Centre 1992; Report No 32. Available at: http://www.monash.edu/ data/assets/pdf file/0019/217153/muarc032.pdf. Accessed November 4, 2016.

Cameron M, Newstead S, Vulcan P, Finch C. Effects of the compulsory bicycle helmet wearing law in Victoria during its first three years. Proceedings of the Pedestrian and Bicyclist Safety and Travel Workshop; 1994: 165-176.

Cripton PA, Dressler DM, Stuart CA, Dennison CR, Richards D. Bicycle helmets are highly effective at preventing head injury during head impact: head-form accelerations and injury criteria for helmeted and unhelmeted impacts. Acc Anal Prev 2014; 70: 1-7.

Cummings $\mathrm{P}$, Rivara FP, Thompson DC, Thompson RS. Misconceptions regarding case-control studies of bicycle helmets and head injury. Accid Anal Prev 2006; 38:636-643.

DiGuiseppi CG, Rivara FP, Koepsell TD, Polissar L. Bicycle helmet use by children: Evaluation of a community-wide helmet campaign. JAMA 1989; 262:2256-2261.

Dill J, McNeil N. Four types of cyclists? Examination of typology for better understanding of bicycle behavior and potential. Transport Res Rec 2013; 2387:129-138.

Elvik R. Corrigendum to:'Publication bias and time-trend bias in meta-analysis of bicycle helmet efficacy: a re-analysis of Attewell, Glase and McFadden, 2001' [Accid Anal Prev 10 2011;43:1245-51]. Accid Anal Prev 2013;60:245-53.

Finch CF, Heiman L, Neiger D. Bicycle use and helmet wearing rates in Melbourne, 1987 to 1992: The influence of the helmet wearing law. Monash University Accident Research Centre 1993; Report No 45. Available at: http://www.monash.edu/ data/assets/pdf file/0016/217051/muarc045.pdf. Accessed November 4, 2016.

Greenberg RS, Daniels SR, Flanders DW, Eley JW, Boring JR. Medical Epidemiology, $3^{\text {rd }}$ ed. East Norwalk, Connecticut: Appleton \& Lange; 2001.

Holcomb WL, Chaiworapongsa T, Luke DA, Burgdorf KD. An odd measure of risk: use and misuse of the odds ratio. Obstet Gynecol 2001;98(4):685-688. 
Marshall SW. Injury case-control studies using "other injuries" as controls. Epidemiology 2008; 19 : 277-279.

McDermott FT, Lane JC, Brazenor GA, Debney EA. The effectiveness of bicyclist helmets: A study of 1710 casualties. Journal of Trauma 1993; 34: 834-45.

McIntosh AS, Lai A, Schilter E. Bicycle helmets:head impact dynamics in helmeted and unhelmeted oblique impact tests. Traffic Inj Prev 2013;14:501-08.

McNally DS, Whitehead S. A computational simulation study of the influence of helmet wearing on head injury risk in adult cyclists. Accid Anal Prev 2013;60:15-23.

Netherlands Institute for Social Research. Mobility Research Netherlands; 2008. Available at: https://www.scp.nl/Onderzoek/Bronnen/Beknopte onderzoeksbeschrijvingen/Mobiliteitsonderzoek Nederland MON. Accessed November 4, 2008.

Olivier J, Creighton P. Bicycle injuries and helmet use: a systematic review and meta-analysis. Int J Epidemiol 2017;46:278-292.

Ormel W, Klein Wolt K, den Hertog P. Enkelvoudige Fietsongevallen: Een LIS-vervolgonderzoek [Single bicycle accidents: An LIS follow-up study]. Amsterdam, The Netherlands: Consument \& Veiligheid; 2008. Available at:

http://www.fietsberaad.nl/library/repository/bestanden/Onderzoek Enkelvoudige fietsongevallen. pdf. Accessed November 4, 2016.

Robinson DL. Head injuries and bicycle helmet laws. Accid Anal Prev 1996; 28(4): 463-475.

Romanow NR, Hagel BE, Williamson J, Rowe BH. Cyclist head and facial injury risk in relation to helmet fit: A case-control study. Chronic Dis Inj Can 2014;31(1):1-7.

Sistrom CL, Garvan CW. Proportions, odds and risks. Radiology 2004;230:12-19.

Smith NC, Milthorpe FW. An observational survey of law compliance and helmet wearing by bicyclists in New South Wales - 1993. Roads and Traffic Authority 1993. Available at: http://www.rms.nsw.gov.au/documents/roads/bicycles/bicycles-law-compliance-helmet-use-nsw1993.pdf. Accessed November 4, 2016.

Thompson RS, Rivara FP, Thompson DC. A case-control study of the effectiveness of bicycle safety helmets. New England Journal of Medicine 1989; 320: 1361-7.

Thompson DC, Thompson RS, Rivara FP, Wolf ME. A case-control study of the effectiveness of bicycle safety helmets in preventing facial injury. American Journal of Public Health 1990; 80: 1471-4.

Woolsgrove C. Helmet effectiveness research forced to go back to the drawing board. European Cyclists Federation. Available at: https://ecf.com/news-and-events/news/helmet-effectivenessresearch-forced-go-back-drawing-board. Accessed November 4, 2016.

Zeegers T. (2015) Overestimation of the effectiveness of the bicycle helmet by the use of odds ratios. International Cycling Safety Conference, 2015, Hanover, Germany. 
Zhang J, Yu KF. What's the Relative Risk? A method of correcting the odds ratio in cohort studies of common outcomes. JAMA 1998;280(19):1690-1691. 
Table 1: $2 \times 2$ contingency table for a case-control study of helmet effectiveness

\begin{tabular}{lcc}
\hline & Case & Control \\
\hline Helmet & $\mathrm{a}$ & $\mathrm{b}$ \\
No Helmet & $\mathrm{c}$ & $\mathrm{d}$ \\
\hline
\end{tabular}

Table 2: Odds ratios and relative risks for Seattle and Victorian studies

\begin{tabular}{lrrrrrrrrr}
\hline & \multicolumn{2}{c}{ Cases } & \multicolumn{2}{c}{ Controls } & Prop & & & $\begin{array}{r}\text { Zeegers' } \\
\text { Study }\end{array}$ \\
\cline { 2 - 8 } & H & NH & H & NH & Helmet & OR & RR & Estimate \\
\hline Thompson et al (1989)+ & 3 & 140 & 12 & 190 & & 0.339 & & 1.28 \\
$\quad$ May 1987 Survey & & & & & 0.046 & & 0.444 & \\
$\quad$ September 1987 Survey & & & & & 0.065 & & 0.308 & \\
McDermott et al (1993) & & & & & & & & 0.66 \\
$\quad$ Head Injury & 55 & 468 & 206 & 876 & 0.250 & 0.500 & 0.353 & \\
$\quad$ Serious Head Injury & 7 & 62 & 206 & 876 & 0.250 & 0.480 & 0.339 & \\
\hline
\end{tabular}

+ School aged children only

Table 3: Numbers of injured NSW cyclists in a motor vehicle collision by helmet use and head injury severity

\begin{tabular}{lrrrrrrrr}
\hline & \multicolumn{2}{c}{ Cases } & \multicolumn{2}{c}{ Hosp } & \multicolumn{2}{c}{ Alt } & \multicolumn{2}{c}{ OR } \\
\cline { 2 - 9 } & H & NH & H & NH & H & NH & Hosp & Alt \\
\hline Thompson et al (1989)+ & & & & & & & & \\
$\quad$ Head Injury & 17 & 218 & 103 & 330 & 130 & 428 & 0.250 & 0.257 \\
$\quad$ Serious Head Injury & 4 & 95 & 103 & 330 & 130 & 428 & 0.135 & 0.139 \\
Bambach et al (2013)* & & & & & & & & \\
$\quad$ Head Injury & 372 & 267 & 924 & 296 & 4715 & 1391 & 0.446 & 0.411 \\
$\quad$ Serious Head Injury & 139 & 133 & 924 & 296 & 4715 & 1391 & 0.335 & 0.308 \\
\hline
\end{tabular}

Alternative controls were collected from $(+)$ surveys and $\left({ }^{*}\right)$ police reported cycling crashes with a motor vehicle 


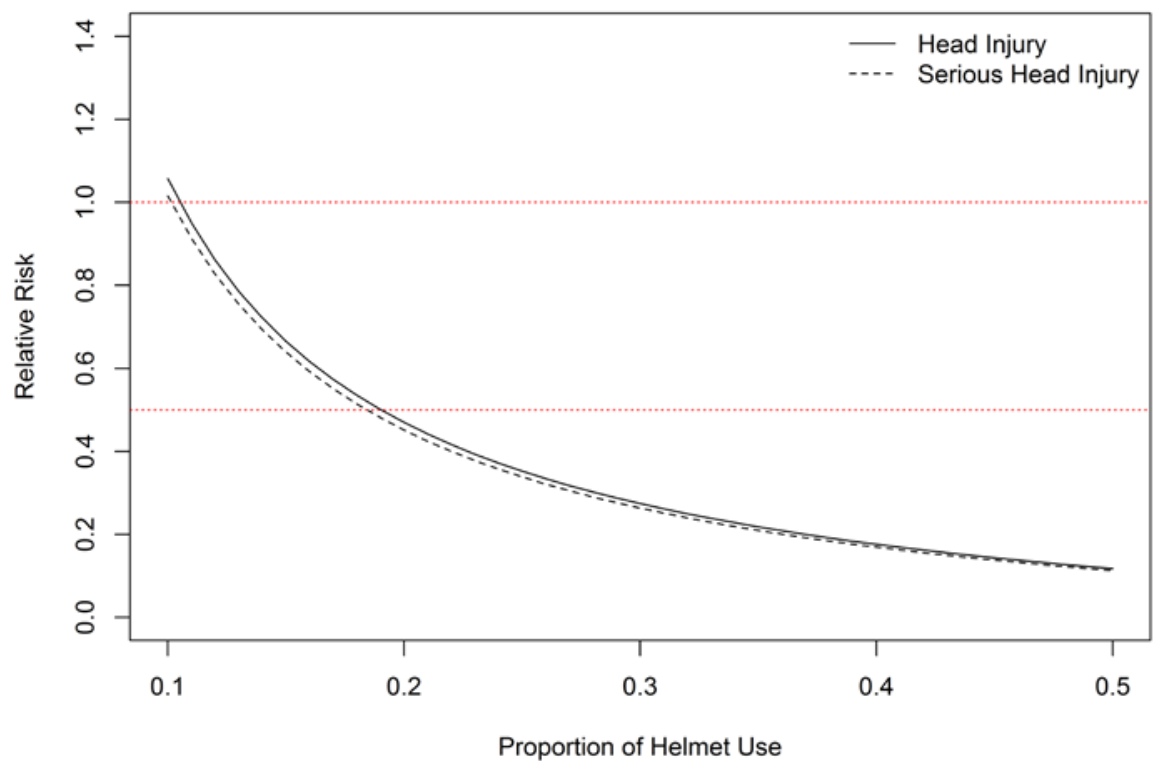

Figure 1: Estimates of relative risk for cycling head and serious head injury by proportion of helmet use for Melbourne \& Geelong, Victoria (1987-1989) 